\title{
Jocelyn Royé, La figure du pédant de Montaigne à Molière
}

\section{Gabriella Bosco}

\section{(2) OpenEdition}

1 Journals

\section{Edizione digitale}

URL: http://journals.openedition.org/studifrancesi/8132

DOI: 10.4000/studifrancesi.8132

ISSN: 2421-5856

\section{Editore}

Rosenberg \& Sellier

\section{Edizione cartacea}

Data di pubblicazione: 1 juillet 2009

Paginazione: 459

ISSN: 0039-2944

\section{Notizia bibliografica digitale}

Gabriella Bosco, «Jocelyn Royé, La figure du pédant de Montaigne à Molière», Studi Francesi [Online], 158 (LIII | II) | 2009, online dal 30 novembre 2015, consultato il 09 janvier 2021. URL: http://

journals.openedition.org/studifrancesi/8132 ; DOI: https://doi.org/10.4000/studifrancesi.8132

Questo documento è stato generato automaticamente il 9 janvier 2021.

\section{(c) (i) (9)}

Studi Francesi è distribuita con Licenza Creative Commons Attribuzione - Non commerciale - Non opere derivate 4.0 Internazionale. 


\title{
Jocelyn Royé, La figure du pédant de Montaigne à Molière
}

\author{
Gabriella Bosco
}

\section{NOTIZIA}

JOCELYN ROYÉ, La figure du pédant de Montaigne à Molière, Genève, Librairie Droz, 2008, pp.

235.

1 Tra la fine del xVI e l'inizio del Xvis secolo, la caratterizzazione comica del Pedante - di origine italiana, come l'etimologia del termine - diventa topos. A finire nel mirino degli autori che fanno di questo personaggio il Ridicolo per eccellenza, sono tanto il suo aspetto fisico, quanto il valore intellettuale e la dimensione morale e sociale del Pedante. In origine connotato non negativamente, quasi sinonimo di pedagogo, l'appellativo assume vieppiù carattere spregiativo, a mano a mano che la figura corrispondente viene identificata con la personificazione della forma più comica di dicotomia tra essere e apparire: l'universitario sentenzioso il cui gergo incomprensibile ha il suo correlativo oggettivo in una condotta avvilente.

2 Ma con il prendere corpo del personaggio in quanto oggetto di satira, si delineano anche le condizioni esemplari per l'avvio di una schermaglia di tipo culturale: l'accusa di "pedantismo" che gli autori si scagliano l'un l'altro diventa ben presto uno dei perni inevitabili di ogni querelle di natura letteraria.

3 Jocelyn RoYé ricostruisce, in questo saggio denso e ricco, la storia e le evoluzioni sia del personaggio che del suo trattamento in ambiti e generi diversi: dalla commedia alla poesia satirica, dalle histoires comiques al romanzo. Se è vero, come ha scirtto Jean Mesnard, che «l'ideale intellettuale e letterario del XVII secolo si definisce in reazione contro lo spirito universitario e contro il tipo del pedante», era ora che uno studio sistematico venisse riservato alla questione, sinora affrontata in questo o quell'autore (Madeleine Lazard a proposito di Pierre de Larivey, Patrick Dandrey sul pedante 
secondo Molière, Jacques Prévot secondo Cyrano de Bergerac e gli scrittori libertini) o in un genere specifico (Robert Horville sul teatro del primo Seicento).

4 Tre i capitoli del saggio. Il primo, e più corposo, traccia "Le portrait du pédant" (pp. 25-113) partendo dalla sua genealogia (repertorio medievale, pedante italiano, commedie rinascimentali, teatro, romans e histoires comiques del xvII secolo) per poi delineare la sua identità, fornirne la descrizione fisica e vestimentaria, il ritratto morale, il comportamento sociale (in famiglia, con le donne, nei confronti dei domestici) e il suo atteggiamento rispetto alla scuola: il percorso va da Montaigne a Molière. Il secondo capitolo, "Le langage pédantesque" (pp. 115-143), analizza la lingua parlata dal pedante, in rapporto sia al latino sia al francese, ne studia lessico e sintassi, e in ultimo la degenerazione patologica. Il terzo capitolo, invece, che si focalizza sul "pédantisme de la Rive Droite", studia l'evoluzione del pedante in quanto letterato mondano e l'epoca in cui l'accusa di pedantismo viene a colpire un ambiente sociale chiaramente identificabile.

5 Chiudono il volume una corposa, esauriente bibliografia (pp. 199-222) e gli indici dei nomi, delle opere e dei personaggi di pedante, maschili e femminili. 